\title{
Ferias comerciales en Guatemala y El Salvador vistas por la prensa del siglo XIX
}

\section{Trade Fairs in Guatemala and El Salvador as Perceived by the Nineteenth Century Press}

\author{
Armando Méndez Zárate \\ https://orcid.org/0000-0003-0586-5807 \\ Universidad Nacional Autónoma de México, Centro de Investigaciones Multidisciplinarias \\ sobre Chiapas y la Frontera Sur. Becario del Programa de Becas Posdoctorales de la UNAM \\ armando.mendez.zarate@gmail.com
}

Resumen

Las ferias comerciales de Guatemala y El Salvador en el siglo XIX fueron espacios de intercambio económico y encuentro social muy activos, pero ¿qué se informaba en la prensa guatemalteca y salvadoreña acerca de estas ferias? y ¿cómo las afectaban la inestabilidad económica, las guerras civiles y los cambios políticos que se vivían en ambos territorios centroamericanos? La revisión de informes y noticias al respecto permite explorar a detalle la influencia que tuvieron en las transformaciones sociales, económicas y culturales, pues retratan elementos relevantes del proceso de formación de los Estados, además de abrir una ventana a la vida cotidiana de la Centroamérica decimonónica.

Palabras clave: comercio, caminos, periódicos, historia cultural, Centroamérica.

\section{Abstract}

Trade fairs in Guatemala and El Salvador during the nineteenth century were very active spaces for economic exchange and social gathering, but what was reported in the Guatemalan and Salvadoran press about these fairs? And how were they affected by the economic instability, civil wars, and political changes that were taking place in both Central American territories? The review of reports and news articles in this regard allows us to explore in detail the influence they had on the social, economic and cultural transformations, since they portray relevant elements of the process of formation of the States, in addition to opening a window to the daily life of nineteenth-century Central America .

Keywords: Trades, highways, newspapers, cultural history, Central America. 


\section{Introducción}

E

n 2018, cuando realizaba una clasificación de hemerografía centroamericana del siglo XIX, logré identificar algunas noticias y crónicas sobre las ferias comerciales de la región, las cuales eran retomadas en niveles diferentes que iban desde la nota circunstancial hasta el informe detallado de su realización. Los periódicos relataban cómo los pueblos y ciudades de Guatemala y El Salvador se preparaban para realizarlas, vinculadas en su mayoría a las festividades católicas. Sin embargo, es importante precisar que el concepto de ferias comerciales que interesa aquí es distinto del de aquellas asociadas con las funciones religiosas católicas celebradas en honor a los santos, las vírgenes y otras solemnidades.

El propósito de este trabajo es reconocer la relevancia de estos encuentros ocurridos en contextos de inestabilidad política y económica, además de abrir una ventana a la vida cotidiana de la Centroamérica decimonónica. Al respecto, se considera que el estudio de las ferias permite explorar a detalle las transformaciones sociales, económicas y culturales en Guatemala y El Salvador, pues retratan elementos relevantes del proceso de formación del Estado.

De ese modo, el análisis de las noticias, informes de corregidores y de jefes políticos, así como de avisos financieros, impresiones de viajeros y publicaciones religiosas revela cómo el comercio y la sociedad encontraron maneras de mantenerse activas a pesar de las guerras civiles y los cambios sociopolíticos. Entonces, las ferias comerciales pueden dejar de mencionarse como hechos anecdóticos, aislados y desconectados de los procesos y las coyunturas. Esto último sin dejar de advertir que la temporalidad de análisis es un lapso de cambios radicales políticos, económicos y sociales; en especial después de la disolución de la Federación Centroamericana, a finales de la década de 1830, y de las llamadas reformas liberales de 1871 en Guatemala y El Salvador.

Me interesa proponer un análisis de las ferias comerciales que permita avanzar en su conocimiento, el cual es aún fragmentado y escasamente abordado. Además, ayudarnos a identificar cómo y cuándo se organizaban las ferias, qué se comerciaba, cuál era el impacto fiscal y económico para los pueblos y ciudades, y por qué eran tomadas como una herramienta de fomento para el desarrollo. Los tres primeros apartados del trabajo están enfocados en discutir esas cuestiones. No obstante, insisto en mi propuesta de examinar las ferias como espacios de esparcimiento que reflejaban la identidad, las diversiones populares y los imagi- 
narios de una sociedad que estaba en el tránsito de la época colonial a la formación de las repúblicas independientes.

Las reflexiones anteriores fueron posibles a partir de la revisión de los siguientes periódicos guatemaltecos: la Gaceta de Guatemala, El Guatemalteco, El Noticioso, El Tiempo y El Progreso, impresos en la Ciudad de Guatemala entre 1840 y 1880. Y para el caso de El Salvador se consultaron El Diario del Salvador, La Gaceta del Gobierno del Salvador, El Siglo y Regeneración, publicaciones que circularon en San Salvador y San Vicente desde 1849 hasta 1890.

\section{Las ferias comerciales centroamericanas}

Las ferias comerciales fueron espacios de encuentro social y económico; se destacaron por comercializar mercancías, ganados y productos agrícolas entre las regiones de Centroamérica. Su organización se remonta a la época colonial, y algunas se mantuvieron vigentes hasta después de la independencia, en 1821. Por ejemplo, en Guatemala sobresalieron las de Esquipulas y Chiantla, y en El Salvador las de San Vicente y San Miguel.

En general, las ferias coincidían con el calendario litúrgico y el santoral católico, y esa herencia colonial se mantuvo durante el siglo XIX. Posteriormente, a partir de 1871, con las reformas liberales en ambos países, la llegada de la libertad de cultos y el enfrentamiento entre el Estado y la Iglesia católica también trascendió la secularización de las ferias. De este modo, los encuentros ajustaron sus fechas para que coincidieran con los ciclos anuales de cosechas, especialmente para el intercambio de mercancías, productos agrícolas y ganados «orientados al pequeño comercio y... las necesidades de consumo» locales (Rodríguez, Muñoz y González, 2013: 458).

Así, las conmemoraciones cívicas se abrieron paso como momentos relevantes en los calendarios nacionales. Por ejemplo, en San Salvador las ferias cívicas, que se empataron con las funciones religiosas durante el siglo XIX, resultaron útiles para crear y consolidar el sentimiento de pertenencia a una nación (López, 2011). Este mismo fenómeno apareció en Guatemala con la feria de Quetzaltenango, la cual coincidía con la celebración del aniversario de la independencia. ${ }^{1}$

Sin embargo, las ferias comerciales estuvieron más enfocadas en el intercambio del añil. Resulta que la demanda exterior de esas tintas naturales po-

\footnotetext{
1 El Guatemalteco, 21 de junio de 1884, año XI, núm. 494, Ciudad de Guatemala, "Crea dos ferias anuales", p. 4.
} 
tenció la formación de mercados regionales en la zona oriental de El Salvador y Guatemala (Herrera y Rojas, 1998; Luján, 1980; Pérez, 2018). El añil ocupó un papel principal en la producción y el comercio en esos territorios desde la época colonial (Fernández, 2013). Los ingresos generados por las tintas engrosaban las arcas nacionales y locales por vía de las alcabalas y otros derechos. Además, los comerciantes mayoristas sabían sacar provecho del añil, acaparando la oferta de los «poquiteros» ${ }^{2}$ y especulando con los precios.

Los poquiteros «vendían su producción en condiciones poco favorables a comerciantes [mayoristas] que lo incorporaban al circuito mercantil» (Acosta, 2015: 108). Para ellos resultaba muy difícil esquivar los pagos de derechos de alcabalas internas y externas que persistieron en Guatemala y El Salvador durante el siglo XIX. De esta forma cobraron gran importancia las ferias, pues en ellas se abrían espacios para negociar entre productores y comerciantes.

Como puede observarse, las tintas naturales permitieron cierto dinamismo económico en Centroamérica, y fueron una fuente de ingresos después de la independencia. Los gobiernos locales dependían de la recaudación de los gravámenes por la exportación del añil para sostener su hacienda. Esos recursos eran muy necesarios para Guatemala y El Salvador, pues ambos Estados debían afrontar gastos derivados de los continuos enfrentamientos armados y de los salarios del aparato burocrático (Fernández, 2003; Lindo-Fuentes, 1995; Luján, 1980; Pérez, 2018; Rubio, 1976).

Ahora bien, ¿cómo eran las ferias comerciales? Estas fueron retratadas en una nota editorial del periódico guatemalteco El Progreso, que describe los encuentros de la siguiente manera:

[Las ferias se celebran] hacia ciertos días o épocas del año periódicamente consagradas a la exhibición de sus productos naturales o industriales con el objeto de venderlos o cambiarlos mutuamente, congregándose al efecto en el lugar de la exhibición comerciantes, agricultores, fabricantes y multitud de curiosos pertenecientes a todas las clases sociales. Estas asambleas llamadas ferias tienen lugar en ciudades o pueblos que gozan de este privilegio por concesiones especiales de los gobiernos o autoridades inmediatas o bien en virtud de costumbres establecidas cuyo origen a menudo se pierde en las nieblas de la tradición. ${ }^{3}$

\footnotetext{
2 Los «poquiteros» eran sembradores y productores de añil en escala pequeña. Ese término aplicaba para los cultivadores y cosecheros de añil desde la época colonial en la Nueva España y el Reino de Guatemala (véase Moziño, 1799).

3 El Progreso, 13 de septiembre 1874, serie 3, núm. 35, Guatemala, "Feria de Jocotenango", p. 2.
} 
En buena medida, el texto puntualiza la índole de las «asambleas» sociales celebradas en Guatemala. Lo mismo se puede mencionar sobre las organizadas en El Salvador, e incluso es posible ampliar esta perspectiva a otros territorios contiguos como Chiapas, en México. De este modo, se deben distinguir dos aspectos de las ferias: el económico y el cotidiano. Por ejemplo, fueron una oportunidad para el esparcimiento y las diversiones públicas, como bailes, corridas de toros, paseos a balnearios, veladas, etc. Esas costumbres de las sociedades guatemalteca y salvadoreña se mantenían a pesar de los conflictos bélicos y las carestías económicas provocadas por la inestabilidad política.

La sociedad aprovechaba las ferias para entretenerse en los diferentes eventos, pues estos suponían una distracción ante el clima de tensión constante que se vivía en esa época. Así, las corridas de toros, peleas de gallos, bailes y representaciones teatrales irrumpían en la vida cotidiana (Sagastume, 2015). Esos elementos permiten adentrarnos en las prácticas sociales comunes, pocas veces exploradas por la historiografía. Estas temáticas de la historia cultural y social aún están pendientes de ser exploradas (Sagastume, 2015: 410) para el territorio centroamericano en el siglo XIX.

Las ferias comerciales pueden explicarse a partir de un problema histórico. La historiografía ha insistido en que su creación se debe al comercio de añil (Fernández, 2003; Lindo-Fuentes, 1995). Sin embargo, es necesario incorporar al menos dos variantes de análisis: una regional y otra social, que permitan entender las dinámicas productivas regionales y contextualizar las vocaciones económicas de cada territorio, en función de sus recursos naturales y su sociedad. Así se podrá observar cómo las economías locales, aparentemente periféricas, se articulaban con los centros principales, y entender cómo reaccionaban esos polos de producción y comercio en coyunturas concretas de inestabilidad política y social.

\section{Las ferias comerciales de Guatemala: añil, granos y ganados}

En Centroamérica, la feria más reconocida por su carácter religioso y comercial es la de Esquipulas, celebrada hasta la actualidad cada año en el oriente guatemalteco entre el 1 y el 15 de enero. Durante la época colonial la festividad atraía a peregrinos de todos los rincones del istmo centroamericano, movidos por la fe hacia el milagroso Señor Crucificado de Esquipulas (Paz, 1904). Los comerciantes aprovecharon las funciones religiosas y establecieron un punto de encuentro 
comercial dedicado a la compraventa de añil, productos agrícolas y mercancías para la venta al mayoreo y menudeo. Después, todo lo intercambiado era distribuido desde Chiapas hasta Costa Rica (Fernández, 1985) por medio de los circuitos comerciales. En este sentido, para el siglo XIX, en Chiapas existían al menos cuatro ferias, que se celebraban con regularidad en San Cristóbal, Tuxtla, Palenque y Comitán (Torres, 2020: 172). La de Comitán, celebrada en enero, es relevante por su vinculación comercial con el occidente de Guatemala.

Los negociantes no dudaban en asistir a la cita anual en Esquipulas, a pesar de los costos por el traslado y las alcabalas que debían pagar por transitar los caminos, las rutas sinuosas, y del riesgo de mover sus productos hasta el oriente guatemalteco, pues las ganancias "les hacían valer la pena de atravesar en lomo de mula" (Fernández, 1985: 57) los parajes y rutas peligrosas. Para ellos la feria de Esquipulas era garantía de buenas utilidades, siempre y cuando los factores externos como las guerras, epidemias, malas cosechas de añil y granos no obstaculizaran la reunión de los peregrinos y la llegada de agentes comerciales.

Desde una perspectiva regional, durante el siglo XIX el encuentro de Esquipulas tuvo indudables repercusiones económicas (Sarazúa, 2013; Torres, 2020: 172). Ahí los comerciantes determinaban el precio del añil (Fernández, 2003) y fijaban el costo de las tintas para las ferias que se celebrarían el resto del año. De esta forma se consolidaba un mercado activo de valores determinado por ese producto. Esto demuestra la existencia de una economía articulada en función del añil.

No obstante, aún desconocemos más a fondo los mecanismos de intercambio implementados por los agentes comerciales añileros locales y externos que nos permitan hilar las vicisitudes de la historia económica en la escala individual o empresarial colectiva (Cipolla, 1991:15), fundamentada por el comercio de las tintas naturales. Al respecto, aún existe un campo muy amplio por explorar, que nos informe sobre el resto de productos y mercancías intercambiados en las ferias, a pesar del dominio del añil (véase cuadro 1).

También las autoridades locales y nacionales guatemaltecas y salvadoreñas intervinieron en las ferias: fomentaban su crecimiento y las establecían en otros puntos, con el objetivo de obtener recursos por el cobro de impuestos y derechos derivados de las transacciones comerciales ahí celebradas (Pinto, 2012: 186; Sarazúa, 2013: 34). De esta manera, los gobiernos guatemaltecos trataron de crear las condiciones idóneas para que los "negociantes contaran con [toda] la seguridad posible" ${ }^{4}$ durante los días de feria. De hecho, en el mandato de Rafael

${ }^{4}$ Gaceta de Guatemala, viernes 22 de diciembre de 1854, tomo VII, núm. 35, Guatemala, "Feria de Escuintla", p. 6. 
Carrera, los corregidores políticos de Guatemala, que fungían principalmente como autoridades intermedias entre el gobierno nacional y el municipal, tuvieron la responsabilidad de promoverlas en sus respectivas demarcaciones.

Cuadro 1. Ferias comerciales de Guatemala

\begin{tabular}{|c|c|c|c|}
\hline Feria & Temporada del año & Características & Tipo de comercio principal \\
\hline Esquipulas & 1-15 de enero & Comercial y religiosa & Añil, mercancías, ganados \\
\hline Escuintla & Primera quincena de febrero & Comercial & Agricultura y ganadería \\
\hline Jocotenango & Mediados de agosto & Comercial y religiosa & Ganadera \\
\hline Huehuetenango & Julio & Comercial y religiosa & Agricultura y ganadería \\
\hline Chiantla & Febrero y septiembre & Comercial y religiosa & Tejidos de lana, ganados \\
\hline Quetzaltenango & 14 al 17 de septiembre & Comercial y cívica & Mercancías y ganados \\
\hline Jutiapa & 15 de noviembre & Comercial y ganadero & Añil y ganadería \\
\hline Chiquimula & Principios de Agosto & Comercial & Mercancías y añil \\
\hline Retalhuleu & Mediados Agosto & Comercial y religiosa & $\begin{array}{l}\text { Mercancías y productos } \\
\text { agrícolas }\end{array}$ \\
\hline
\end{tabular}

Fuente: elaboración propia con base en las notas de los periódicos consultados.

Por otra parte, los habitantes de las localidades en las que transcurrían las ferias veían trastocada su cotidianidad. La presencia masiva de personas atraídas por las diversiones públicas como palenques, corridas de toros y otras distracciones asociadas con la embriaguez llegó a salirse de control; no dejaban de ocurrir riñas, homicidios y otros tumultos. ${ }^{5}$ Poco se sabe con respecto a las distracciones populares y sus implicaciones sociales, con excepción de algunos trabajos para el ámbito urbano de la Ciudad de Guatemala de Tania Sagastume (2017).

El análisis de las ferias nos permite conocer aspectos cotidianos de las costumbres en los espacios rurales. Las notas e informes de los periódicos son más que una crónica de los eventos feriales, pues ayudan a comprender cómo la sociedad de la época afrontaba los acontecimientos políticos, los conflictos armados y las crisis económicas. A pesar de esos contratiempos, los encuentros feriales se mantuvieron y extendieron en el territorio guatemalteco, además de consolidarse como lugares de intercambio económico y disfrute social.

En este sentido, los estudios de historia cultural y social se han abierto paso paulatinamente en Centroamérica al abordar otros aspectos cotidianos de la sociedad, en contextos y coyunturas que solo se habían ocupado de documentar

5 El Tiempo, 16 de febrero de 1840, núm. 77, Guatemala, "Informe sobre el estado de los departamentos, Chiquimula", p. 307. 
y reflexionar sobre los hechos de la historia política y militar, la cual se destacaba por su corte nacionalista. La ruptura con esas temáticas surgió a partir del análisis de la vida diaria, las diversiones públicas y algunos aspectos culturales (Dary, 1993; Urbina, 2006). Además, del texto coordinado por Brian Connaughton (2017) sobre la época de Rafael Carrera (1844-1865), en el que se incorpora una mirada poliédrica de ese periodo político, con especial énfasis en la forma en que se divertía el común de la población.

Al respecto, la transformación más relevante en la organización y celebración de las ferias en Guatemala ocurrió a partir de las reformas liberales de 1871. El programa de gobierno de los revolucionarios liberales pugnaba por implementar una ideología laica que rigiera en todas las actividades del Estado (Kendall, 1991). De este modo, las ferias tendrían que separarse de las funciones religiosas y apegarse al calendario de festividades cívicas nacionales, como el aniversario de la independencia o la promoción económica de un producto.

Sin embargo, las disposiciones liberales sobre las ferias fueron adoptadas de forma parcial. La fuerza de la costumbre y hasta las circunstancias climáticas obligaban a las autoridades a tolerar celebraciones ajustadas a las festividades religiosas. La feria de Jocotenango continuó coincidiendo con el ejercicio devoto de tres días, entre el 13 y 15 de agosto, conocido como triduo, en honor a la Virgen de la Purísima Concepción. Según las noticias recogidas de los diarios, en Jocotenango "solo se trafica[ba] con ganado vacuno, caballar y mular", ' con tanto éxito que las autoridades decidieron concentrar ahí otras ferias que se realizaban en lugares cercanos, como la de San Andrés Iztapa, que en 1878 fue trasladada a Jocotenango.?

También existieron otras reuniones ganaderas muy exitosas, como la de Chiantla, en Huehuetenango, la cual logró protagonismo en el comercio guatemalteco, pues se efectuaba en dos momentos al año: en febrero y durante los "días de la natividad", en septiembre. ${ }^{8}$ La movilización de ganados era alentada por el tráfico legal y el comercio ilegal que conectaba Chiantla con otros lugares como Comitán y Ciudad de Guatemala (Sarazúa, 2018: 60).

Las ferias ganaderas celebradas dos veces al año, como la de Chiantla o Jocotenango (véase cuadro 1), obedecían a una lógica determinada por las con-

\footnotetext{
6 El Progreso, 13 de septiembre 1874, serie 3, núm. 35, Guatemala, "Feria de Jocotenango", p. 2-3.

7 El Guatemalteco, 24 de agosto de 1878, tomo V, núm. 183, Guatemala, "Oficial", p. 4

8 Gaceta de Guatemala, 22 de septiembre de 1854, tomo VII, núm. 22, Guatemala, "Corregimiento", p. 2.
} 
diciones climáticas. Las personas y comunidades indígenas aprovechaban la pausa del temporal con la canícula, entre julio y agosto, para movilizar sus animales a los recintos feriales y venderlos. Ese tiempo les resultaba idóneo, pues no interrumpían sus labores en el campo y podían obtener ganancias que les permitieran subsistir hasta contar con los recursos obtenidos de las cosechas entre noviembre y diciembre.

En las regiones agrícolas altamente productivas también las estaciones climáticas determinaban las fechas de los encuentros. Por ejemplo, en la boca costa guatemalteca, en Escuintla, tenía lugar una reunión anual durante la primera quincena de febrero, donde destacaba el intercambio de productos agrícolas, además de distinguirse por ser "muy concurrida y animada". . La cercanía con la Ciudad de Guatemala ayudó a la feria de Escuintla a tener un flujo de personas constante, y el clima cálido de la temporada también resultaba ideal para la organización de paseos por sus campos.

Las noticias de los periódicos mencionan con insistencia que las poblaciones competían con sus ferias para especializarse en ciertos sectores de la economía, con la intención de diferenciarse y atraer a comerciantes, agentes y paseantes. La especialización en el comercio de mercancías y productos agrícolas dependía de la forma en que los habitantes aprovechaban los recursos naturales del territorio que ocupaban. De esta manera, era comprensible que las ferias del oriente de Guatemala destacaran por el intercambio a gran escala del añil proveniente de El Salvador, en contraste con el occidente guatemalteco, donde las mercancías y ganados tuvieron mayor preponderancia durante la primera mitad del siglo XIX.

En consecuencia, las ferias del oriente de Guatemala dependieron de los encuentros feriales del occidente salvadoreño, como la de Los Santos de Ahuachapán. ${ }^{10}$ En ese lugar se colocaban los productos agrícolas y las mercancías de las regiones circundantes, y posteriormente era distribuidas al resto de las ferias que se celebraban en otros lugares aledaños. Precisamente, las autoridades ordenaron el establecimiento de una feria en Jutiapa en 1868 con el objetivo de reactivar el comercio añilero proveniente de El Salvador, seriamente afectado por la pérdida de valor de la tinta (Lindo-Fuentes, 1994: 73) y promocionar la producción ganadera y agrícola de los departamentos de Jutiapa, Santa Rosa y Chiquimulilla. ${ }^{11}$ Sin embargo, por la urgencia de atender esos problemas, por

9 Gaceta de Guatemala, 23 de febrero de 1858, tomo X, núm. 14, Guatemala, "Temporada", p. 1.

10 Diario del Salvador, 26 de agosto de 1907, año XVIII, núm. 3491, San Salvador, "Telegramas", p. 3.

11 Gaceta de Guatemala, 26 enero de 1868, tomo XV, núm. 75, Guatemala, "Acuerdo que se dictan algunas medidas para favorecer la producción de añil en la República", p. 599. 
cuestiones administrativas, la feria de Jutiapa no comenzó a celebrarse hasta 1870.

En este sentido, las autoridades guatemaltecas en el nivel intermedio y nacional tuvieron entre sus atribuciones la de incentivar el comercio y la agricultura de sus respectivas demarcaciones políticas. El reglamento para el gobierno político de los departamentos, municipalidades y alcaldías de 1839 (Marure, 1841) marcaba claramente las responsabilidades que debían observar los funcionarios para promover las industrias. Esas competencias fueron prolongadas por los gobiernos liberales, cuando fue reformado el reglamento en 1879 (Méndez, 2018: 222).

Algunos planteamientos historiográficos, que seguramente habría que matizar, señalaban que si bien las ferias funcionaban como un mecanismo para alentar las economías regionales durante la década de 1860 (Acosta, 2014: 7-8), estas se vieron afectadas por la baja demanda de los tintes naturales en el mercado externo y, después de 1871, por la transición al modelo económico agroexportador cafetalero impulsado por los gobiernos liberales de Guatemala y El Salvador (González-Izás, 2014; Lindo-Fuentes, 1994). Sin embargo, en Guatemala las autoridades las siguieron creando y promoviendo.

Así, sin rendirse ante la crisis del precio y del comercio del añil, el gobierno guatemalteco, en su intento por reactivar ese sector, insistió en el fomento de las ferias como un recurso más para remediar esa debacle, como sucedió con la iniciativa del corregidor de Jutiapa en 1868. Sin embargo, dos décadas después, en 1887 el periodista Virgilio J. Valdés realizó un breve balance sobre la situación de los encuentros comerciales, agrícolas y ganaderos celebrados en Guatemala. En su reporte concluyó que desde 1878 "las autoridades nacionales habían mandado hacer más de veinticinco ferias por todo el país". ${ }^{12}$ Pero una condición era el decreto que otorgaba los permisos para establecer una feria, y otra muy distinta era la práctica, pues muchas de las ferias emanadas de los decretos nunca se llevaron a cabo. De esta forma, de las creadas en 1878 solamente la mitad se efectuaron. ${ }^{13}$

Las juntas locales de fomento eran las encargadas de solicitar al gobierno nacional los permisos para celebrar una feria; y una vez autorizada, el presidente de Guatemala decretaba oficialmente su creación. Con este mecanismo iniciaron las de Chiquimulilla y San Juan Malacatán. ${ }^{14}$ Esta última establecida a partir de 1894

\footnotetext{
12 Revista Agrícola-Comercial, 1 de febrero de 1887, año I, núm. 11, Guatemala, "Ferias", p. 1.

13 Revista Agrícola-Comercial, 1 de febrero de 1887, año I, núm. 11, Guatemala, "Ferias", p. 1.

14 El Guatemalteco, 29 de octubre de 1887, tomo VI, núm. 93, Ciudad de Guatemala, "Oficial", p. 1.
} 
para celebrarse entre el 21 y 25 de diciembre, resultó estratégica para el comercio, debido a que se localizaba en una población fronteriza del departamento de San Marcos, cercana a los límites de México y a ciudades relevantes como Tapachula. Esa región adquirió relevancia política, económica y social, pues desde el establecimiento de la frontera entre México y Guatemala en 1882, los flujos comerciales y agrícolas aumentaron, convirtiéndose en un polo de desarrollo cafetalero transfronterizo (Méndez, 2018).

Igualmente, en Retalhuleu se instauró una feria que se efectuaría del 6 al 12 de diciembre. Los organizadores recibieron bastante apoyo del presidente guatemalteco Manuel Lisandro Barillas. Por ejemplo, en 1886 la municipalidad fue autorizada para otorgar franquicias a comerciantes y agricultores, con lo que trataron de ayudarlos para que pudieran acudir a la feria a ofrecer sus mercancías. ${ }^{15}$ De ese modo, la municipalidad podía allegarse ingresos por el cobro de derechos y los agentes comerciales tenían la posibilidad de colocar sus productos en el mercado. Así, en 1884, el presidente guatemalteco Justo Rufino Barrios publicó el decreto para la creación de esa feria. El motivo principal declarado fue la promoción del comercio, pero también reforzar los lazos identitarios nacionalistas que vincularan el occidente guatemalteco al resto de la nación, debido a que las fechas de realización coincidían con la celebración del aniversario de la independencia. De esta forma, la feria de Xela, como se le conocería posteriormente, tendría la particularidad de ser un encuentro mercantil y resaltar el espíritu nacional. Adicionalmente, Rufino Barrios aprobó la feria comercial en Salcajá, del 18 al 20 de julio, ${ }^{16}$ justo en las cercanías de Quetzaltenango.

Entre lo más significativo de ambas celebraciones destacaban los mandatos encomendados a las municipalidades, que las obligaban a cuidar la organización de las ferias. Era un reto. Las autoridades locales debían destinar terrenos adecuados para la exposición de los productos y contar con un sitio de pasto para el ganado que sería comerciado, o bien para las bestias de carga que traerían los comerciantes. Estas características abrían otra línea temática sumamente interesante: la arriería y el transporte de ganados para su venta en los encuentros feriales.

Otros factores determinantes para el éxito de los encuentros feriales dependían también de las autoridades, como la seguridad y la accesibilidad de los

15 El Guatemalteco, 24 de agosto de 1886, tomo II, núm. 193, Ciudad de Guatemala, "Disposiciones relacionas con la feria de Retalhuleu", p. 789.

16 El Guatemalteco, 24 de agosto de 1886, tomo II, núm. 193, Ciudad de Guatemala, "Disposiciones relacionas con la feria de Retalhuleu", p. 789. 
caminos. Incluso, el circulante monetario, indispensable para efectuar los intercambios de productos, recaía como responsabilidad directa del gobierno. Al respecto, en 1886 el jefe político de Chiquimula señalaba en su informe sobre la feria comercial efectuada en la cabecera departamental que las ventas se habían reducido "por la suma escasez de numerario que experimentan la mayor parte de los pueblos de oriente". ${ }^{17}$ A pesar de las carencias monetarias, el jefe político de Chiquimula indicó que "la cesación de las lluvias permitió que hubiese alguna concurrencia de los pueblos circunvecinos ${ }^{\prime \prime}{ }^{18}$ salvando momentáneamente la situación comercial del departamento.

La circulación de moneda durante el siglo XIX fue un problema en Guatemala y en el resto de los países centroamericanos, pues existían piezas de plata de baja calidad y cortadas, que pasaban como monedas buenas antiguas de plata o macuquina (Jovel, 2001: 50). Los comerciantes que asistían a las ferias tenían que vigilar que el dinero utilizado para los intercambios no fuera falso o rebajado en la cantidad de plata. En los informes de la feria de Chalatenango, los mercaderes estimaban que al menos la cuarta parte de las monedas circulantes eran falsificadas. ${ }^{19}$ También existieron las monedas sudamericanas provenientes de Chile y Perú principalmente, las cuales eran reselladas para ser introducidas al mercado centroamericano (Jovel, 2001: 83-84).

De cualquier forma, hacia finales del siglo XIX la dinámica de organización de las ferias comerciales guatemaltecas y salvadoreñas comenzó a cambiar, a medida que el añil fue desplazado por la producción cafetalera (Cambranes, 1985; LauriaSantiago, 2013; Lindo-Fuentes, 1994; Gónzalez-Izás, 2014). El funcionamiento de la comercialización del café fue diametralmente opuesto al del añil, pues el mercado cafetalero estuvo controlado por empresarios y casas comerciales extranjeras, cobijadas y alentadas por los gobiernos de tendencia liberal en Guatemala y El Salvador, que aprovecharon esta etapa para impulsar una modernización capitalista que irradió a otros sectores sociales y gubernamentales (González-Izás, 2014). Así, los pueblos productores y las personas dedicadas a la cosecha de añil vieron agravada su situación, sobre todo los "poquiteros" que, como ya se dijo, se presentaban en las ferias comerciales para vender su limitada producción a los compradores más grandes que llegaban en búsqueda de las tintas.

17 El Guatemalteco, 24 de agosto de 1886, tomo II, núm. 193, Ciudad de Guatemala, "Informe de la Jefatura Política de Chiquimula", p. 787.

18 El Guatemalteco, 24 de agosto de 1886, tomo II, núm. 193, Ciudad de Guatemala, "Informe de la Jefatura Política de Chiquimula", p. 787.

19 El Mercurio, 15 de julio de 1850, núm. 6838, Valparaíso, Chile, “Crónica extranjera: América Plateresca", p. 1 
Estos elementos reconfiguraron las dinámicas productivas y sociales en el campo guatemalteco. Los cambios en las actividades orillaron a los trabajadores a buscar una salida laboral en las plantaciones cafetaleras (Gould y LauriaSantiago, 2008), bajo condiciones muy penosas. Los indígenas que se movían enganchados a trabajar en las fincas (McCreery, 1994) abandonaban sus pueblos, lo que complicaba su participación en las festividades religiosas y feriales que se organizaban en sus comunidades.

En Guatemala las ferias comerciales tuvieron una preponderancia para los pueblos y ciudades desde la colonia hasta bien entrado el siglo XX. No obstante, el funcionamiento de los encuentros comerciales se alteró con las políticas liberales emprendidas a partir de 1871, las cuales modificaron el perfil económico, cultural y político. En este punto es posible identificar una transformación de estas actividades, que no desaparecieron del todo. Aunque en este trabajo solo se aborda el caso para explorar las continuidades y transformaciones en la celebración de las ferias, resulta necesario continuar con el análisis de estos encuentros enfatizando en las diversiones públicas y en la vida cotidiana de las personas.

\section{Las ferias comerciales añileras y comerciales salvadoreñas}

En El Salvador las ferias más reconocidas se realizaban en San Vicente, San Miguel, Chalatenango y San Salvador (véase cuadro 2); esta última se celebraba dos veces al año, en mayo y agosto. En los encuentros comerciales salvadoreños el añil se destacaba como el producto principal de intercambio. Aunque también llegaban mercancías por vía marítima a los puertos de la Unión, La Libertad y Acajutla, ubicados en las costas del océano Pacífico. Incluso había productos desembarcados en el mar Caribe a través de Izabal (Contestaciones, 1840). Los comerciantes se encargaban de llenar sus inventarios con los géneros ultramarinos y posteriormente las distribuían en las diferentes plazas que celebraban ferias o las transaban a cambio de añil (Pérez, 2012: 138). De esa forma los comerciantes podían almacenar y distribuir mercancías para el resto del año. ${ }^{20}$

Las ferias añileras dependieron de la capacidad de los comerciantes para recolectar y comprar el añil a los poquiteros; el éxito comercial se basaba en esas transacciones. De este modo, la economía regional se fue articulando con los centros productivos de las tintas, además de irradiar con su comercio a otros te-

20 El Siglo, año 1, núm. 33, jueves 22 de mayo de 1851, San Salvador, "El Sr. Morelzoon", p. 1-2; El Siglo, año 1, núm. 34, lunes 19 de mayo de 1851, San Salvador, "Feria de Mayo", p. 1. 
rritorios contiguos en Guatemala. Por ejemplo, en la década de 1830 "cerca de la tercera parte del añil se embarcó en el Pacífico y no vía Belice" (Castellón, 2016: 118). Esos números de exportación coinciden con lo estudiado por Juan Carlos Sarazúa (2007: 152), al encontrar que para 1856, 32\% de la cosecha de añil salvadoreño se exportaba por Guatemala y Honduras. De esta forma, el producto salvadoreño tuvo su salida a los circuitos comerciales terrestres y marítimos por el mar Caribe y el océano Pacífico, hasta llegar a plazas distantes en el Perú y Chile (Castellón, 2016: 118).

Cuadro 2. Ferias comerciales de El Salvador

\begin{tabular}{|c|c|c|c|}
\hline Feria & Temporada del año & Característica & Tipo de comercio principal \\
\hline San Miguel & Septiembre y Noviembre & Comercial y religiosa & Añil y mercancías \\
\hline Chalatenango & Noviembre & Comercial y religiosa & Añil y mercancías \\
\hline San Vicente & Noviembre & Comercial y religiosa & Añil y mercancías \\
\hline San Salvador & Mayo y Agosto & Comercial y religiosa & Añil y mercancías \\
\hline Ahuachapán & Noviembre & Agrícola y comercial & Añil y productos agrícolas \\
\hline Ilobasco & Primera semana de diciembre & $\begin{array}{l}\text { Comercial, agrícola y } \\
\text { religiosa }\end{array}$ & Mercancías y ganados \\
\hline Cojutepeque & Tercer viernes de cuaresma & Comercial y religiosa & Mercancías y ganados \\
\hline Coatepeque & Tercer viernes de cuaresma & Comercial y religiosa & Añil y mercancías \\
\hline
\end{tabular}

Fuente: elaboración propia con base en las notas de los periódicos consultados (Larde y Larin, 1950: 94-95; Monterey, 1996: 315).

En este contexto, en la feria de Chalatenango, aunque estuvo especializada en el comercio de añil, también se distribuían y vendían "mercaderías extranjeras [...] a buenos precios", ${ }^{21}$ provenientes de los puertos principales de El Salvador (Pérez, 2012: 133-134). La llegada de los buques con mercancías procedentes de La Unión, La Libertad y Acajutla robustecían el mercado y la oferta en los días feriales de Chalatenango. Los barcos traían cargas de las casas comerciales sudamericanas que estaban en pleno auge, transitando y comerciando por las plazas portuarias del Pacífico.

Un agente comercial extranjero que visitaba con regularidad las ferias de Esquipulas en Guatemala y la de San Miguel en El Salvador, hizo una parada en el encuentro ferial de Chalatenango y publicó, en 1850, en el periódico chileno El Mercurio, sus impresiones:

21 Gaceta de Guatemala, 26 de octubre de 1865, tomo XIV, núm. 93, Guatemala, "El Salvador" Nota periodística tomada del periódico El Constitucional del 19 de octubre de 1865, p. 4. 
Puesto que la vida de esta pequeña comunidad [Chalatenango] está cifrada en una palabra, feria [sic]. Lo demás del año téngome yo para mi que Chalatenango no existe, o si existe es a manera de las marmotas, que yacen adormecidas el invierno entero y solo despiertan a los primeros calores del estio, con la diferencia de que su sueño se prolonga por once y medio meses, mientras su sol por solos quince días se vivifica. ${ }^{22}$

Sin duda, el relato del comerciante resalta el valor de la feria de Chalatenango y la forma en que los días feriales transformaban a sus habitantes. La narración recupera aspectos relevantes de lo que implicaba la organización y el funcionamiento de una feria. Por ejemplo, la disposición de los puestos de venta, los cuales eran distribuidos alrededor de los portales y consistían en mesas o petates en el piso donde los vendedores exponían las mercancías. Los puestos no se movían durante la noche, pero para evitar cualquier robo se organizaban guardias de vigilancia, aunque había algunos vendedores que preferían "dormir en la misma tienda con sus dependientes y criados sobre el mostrador". ${ }^{23}$

Por las mañanas los puestos de los portales y las tiendas establecidas se disponían a abrir los bultos con las mercancías y posteriormente las acomodaban para su venta. Esto debió implicar todo un arte de montaje, sobre todo por la variedad de géneros y por las condiciones de espacio de cada tienda. Además, los productos expuestos también reflejaban la riqueza del comerciante que los ofrecía. Al respecto, el viajero que visitó Chalatenango registró lo que observó en una tienda:

tejidos de algodón de mil especies, algunos de lino, pañuelos de seda, hilo de tejer y coser, escopetas, cuchillos de punta, espejos de cartón, cuentas de vidrio, zarcillos falsos de Alemania, sillas de montas, platos de loza, juguetes de loza y de madera, tazas de China, agua de Colonia, resmas de papel, cajitas de licores, sardinas de Nantes en latas, canela, etc. ${ }^{24}$

Incluso existió un código no escrito respetado por vendedores y compradores para realizar las transacciones en los puestos y tiendas durante los días de feria. Primero entraban a comprar los dueños de almacenes que ofrecían productos

22 El Mercurio, 15 de julio de 1850, núm. 6838, Valparaíso, Chile, "Crónica extranjera: América Plateresca", p. 1.

23 El Mercurio, 15 de julio de 1850, núm. 6838, Valparaíso, Chile, "Crónica extranjera: América Plateresca", p. 1.

24 El Mercurio, 15 de julio de 1850, núm. 6838, Valparaíso, Chile, "Crónica extranjera: América Plateresca", p. 1. 
provenientes del extranjero y que solo vendían por pieza, docena o bulto. Es decir, se daba prioridad a los mayoristas que tenían sus negocios en El Salvador, Guatemala o el extranjero. Después llegaban los vendedores de segunda clase, llamados "tracheros", que en su mayoría eran mujeres. Finalmente ingresaba la "turba" de "buhoneros ambulantes", los cuales se dividían en dos categorías: "las plazeras" y "los achines". ${ }^{25}$ Las primeras se dedicaban a la venta de trapos y ropas, y los segundos eran hombres que comerciaban hilos y textiles.

Los "buhoneros" deambulaban con los productos de un lugar a otro. Las llamadas placeras iban a los pueblos de mayor tamaño y los achines recorrían los campos y las comunidades rurales. Aunque los buhoneros conformaban una clase de comerciantes, no eran bien vistos debido a que su "moral no es por cierto de mui subidas quilates". ${ }^{26}$ La clasificación de los comerciantes, una muestra de la estratificación social que imperó en El Salvador durante el siglo XIX, aporta elementos de análisis para adentrarse en la vida cotidiana y la historia de género. En este sentido, resultaría sumamente interesante un estudio a profundidad que detallara las actividades y la influencia de las vendedoras placeras en los circuitos comerciales centroamericanos y locales.

El arribo de la "turba" de compradores y paseantes llegó a implicar un problema de logística para las autoridades. Por ejemplo, la feria de San Miguel, en el oriente salvadoreño, era reconocida por concentrar el mayor número de comerciantes de añil provenientes de Honduras y Nicaragua. A pesar de los beneficios que generaba la feria para los habitantes de San Miguel, estos constantemente expresaban sus reclamos al gobierno nacional debido que consideraban que en los días de feria el pueblo se llenaba de "forajidos sin oficio que corrompen los pueblos", ${ }^{27}$ y añadían que también se daba cita "lo peor de cada casta, [como] pillos de profesión, jugadores, ladrones, rateros, etc.". ${ }^{28}$

Las autoridades municipales se encargaban de perseguir a los vagos en los pueblos y ciudades. Este trabajo se intensificaba en la temporada ferial, pues los encuentros sociales alentaban la relajación en las diversiones públicas y la embriaguez. Sin embargo, los aguardientes representaban ingresos importan-

25 El Mercurio, 15 de julio de 1850, núm. 6838, Valparaíso, Chile, “Crónica extranjera: América Plateresca", p. 1.

26 El Mercurio, 15 de julio de 1850, núm. 6838, Valparaíso, Chile, "Crónica extranjera: América Plateresca", p. 1.

27 Gaceta del Gobierno de El Salvador, 5 de mayo de 1848, tomo 1, núm. 58, San Salvador, "Visita del presidente del Estado al departamento de San Miguel" p. 229.

28 El Mercurio,15 de julio de 1850, núm. 6838, Valparaíso, Chile, "Crónica extranjera: América Plateresca", p. 1. 
tes para las municipalidades salvadoreñas (Méndez, 2018), de manera que sería lógico pensar que el consumo aumentaba durante los días de feria, y también proporcionalmente las contribuciones a las arcas municipales, por los derechos cobrados sobre los aguardientes y la venta de permisos para su distribución, a través del remate del estaco de aguardiente.

Las bebidas alcohólicas formaban parte de las costumbres y estaban integradas en las prácticas religiosas de las comunidades indígenas y ladinas de Guatemala y El Salvador, y su producción y comercialización abonaban a la economía local. Los gobiernos locales y nacionales conocían las problemáticas y los disturbios que sucedían por su consumo en exceso (Carey y Taylor, 2012). Sin embargo, no llegaron a prohibir su venta, antes bien, emitieron leyes y decretos para sacar ventajas fiscales de ello (González, 2014), especialmente mediante el remate del estanco de los aguardientes abierto en puja pública, para asignarse a los mejores postores.

El planteamiento anterior comprueba la relación existente entre la fiscalidad y el consumo de alcohol en las ferias. Aunque carecemos de análisis específicos que aborden los impuestos, alcabalas y derechos municipales y nacionales provenientes del comercio ferial (Pérez, 2012). Estos ejercicios permiten aproximarse a los procesos de reorganización institucional y administrativa del Estado salvadoreño. Por ejemplo, la celebración de las ferias demandaba el transporte de las mercancías y el añil desde los centros de producción hasta los puntos de venta, y durante ese tránsito los comerciantes, arrieros y añileros pagaban alcabalas interiores y exteriores. En esos casos intervenía una estructura burocrática con un sistema de operación propio que tuvo repercusiones directas en la obtención de recursos para las municipalidades y el gobierno nacional salvadoreño.

En 1840 los comerciantes que querían ingresar productos a El Salvador debían pagar un impuesto de $20 \%$ sobre el precio de las mercancías, más el $4 \%$ de alcabala interior (Contestaciones, 1840). Las tasas impositivas fiscales obligaban a los comerciantes a trasladar esos costos al precio final de las mercancías y del añil vendido en las ferias. El problema era cuando había poca concurrencia de compradores. Esa situación se refleja en el testimonio de los comerciantes añileros de la feria de llobasco en 1850, cuando manifestaron que por "lo abatido del precio de los añiles... los cosecheros se han quedado con sus tintas". 29 En esas condiciones, los añileros y compradores podían tener pérdidas significativas, ya que lidiaban con las alcabalas y otros impuestos.

\footnotetext{
29 Gaceta de Guatemala, 24 de mayo de 1850, tomo 4, núm. 96, Guatemala, "Feria", p. 387.
} 
A pesar del riesgo en el comercio añilero, los grandes comerciantes consiguieron sortear algunas trabas fiscales. Ellos se abastecían de las tintas naturales en San Miguel y Chalatenango para luego redistribuirlas en Guatemala, o bien embarcarlas hacia Europa y Sudamérica. El mercado permitió que los comerciantes mayoristas de añil y mercancías organizaran un sistema de crédito, el cual se mantuvo activo entre los comerciantes y vendedores finales que participaban en las ferias (Pérez, 2018). Este mecanismo les ayudó a protegerse de las pérdidas ante una baja en los precios, o bien frente a situaciones de poca afluencia a las ferias, como la descrita anteriormente en llobasco.

Por otra parte, en El Salvador también existieron enclaves regionales agrícolas y ganaderos. Aldo Lauria-Santiago (1995) ha explorado estos aspectos para el caso de Cojutepeque y halló una relación directa entre la producción agrícola y las ferias comerciales, las cuales contribuyeron paralelamente a la consolidación del Estado salvadoreño a mediados del siglo XIX. Dichos encuentros fortalecieron la fiscalidad y contribuyeron a las redes de comercio en el interior del país. Además, las regiones adquirieron una vocación agrícola y comercial diferenciada. El oriente de El Salvador despuntó por el tráfico del añil, convirtiéndose en el género de intercambio principal con el resto de Centroamérica y Sudamérica (Pérez, 2018). Mientras que el occidente se perfiló como un centro agrícola y ganadero, vinculado con el oriente guatemalteco, por donde pasaba el añil en su tránsito al mercado del país vecino.

Esas características, permitieron que las ferias comerciales salvadoreñas también coincidieran "con los ciclos agrícolas de la siembra y cosecha del maíz y el añil" (Fernández, 2003: 198). Incluso, la posición geográfica de El Salvador ayudaba a que sus ferias fueran puntos intermedios en las rutas que conectaban Centroamérica (Pérez, 2018), además de ser el paso casi obligado de los caminos provenientes de Nicaragua, Costa Rica y algunos lugares de Honduras hacia la Ciudad de Guatemala. De esta forma, la circulación de personas y noticias permitió que los habitantes se enteraran de viva voz de los acontecimientos políticos y sociales que sucedían en las diferentes regiones centroamericanas.

Estos elementos de la vida cotidiana que podrían pasar inadvertidos para la historia de los grandes acontecimientos políticos y económicos se presentan como ventanas de interpretación de las realidades sociales que vivían y padecían los habitantes de los pueblos y ciudades salvadoreños, particularmente en momentos de agitación política y levantamientos armados. Durante el siglo XIX, el territorio de El Salvador fue el epicentro de las principales batallas y "revolu- 
ciones" que configuraron a los Estados centroamericanos. La intersección de los caminos principales y sus ingresos fiscales por el añil comerciado en sus ferias resultaba en un botín atractivo para los jefes militares, quienes siempre consideraban la ocupación y el control de El Salvador como clave principal para sus planes.

Las autoridades salvadoreñas tuvieron presente la importancia de las ferias comerciales por su capacidad de generar ingresos para las arcas nacionales o bien como herramienta para financiar campañas militares. Al respecto se deben diferenciar las facultades de las autoridades municipales de las intermedias para organizar y fomentar los encuentros comerciales. A partir de 1832 los jefes políticos de El Salvador estaban obligados a promover las ferias que existieran dentro de sus jurisdicciones, ${ }^{30}$ además de establecer otras en donde el comercio demandara su organización (Avendaño, 2019). Por su parte, los alcaldes y regidores en los municipios tenían el mandato de colaborar con los jefes políticos en esa tarea. De este modo, las ferias fueron fomentadas desde el Estado como una medida que impulsaría la agricultura e industria de los departamentos, además de alentar la economía regional (Méndez, 2018: 228; Pérez, 2011: 210).

Las atribuciones de los jefes políticos salvadoreños no fueron disposiciones menores dentro de las normas jurídicas, pues fueron integradas en el texto constitucional de 1864, y se mantuvieron sin alteración en las sucesivas constituciones de El Salvador (1871, 1880 y 1886). Así quedó consolidado un marco legal que dejaba a las municipalidades y a los gobiernos departamentales un margen amplio para intervenir en la creación de ferias e influir en la organización de las ya existentes, especialmente aquellas dedicadas al añil y a la venta de mercancías de importación.

Mas, a pesar de los esfuerzos de las autoridades por alentar y promover las ferias comerciales, hacia finales del siglo XIX comenzó un declive de estas debido a la introducción del café y a los nuevos esquemas de comercialización que implicaba su venta, además de la baja en el precio y en la demanda del añil en los mercados exteriores (Pérez, 2012: 138). Fueron las ferias añileras salvadoreñas las que resintieron esos cambios, pues paulatinamente el negocio dejó de redituar ganancias para todas las partes involucradas en el comercio de las tintas. Ante este escenario, los intermediarios que se daban cita en los encuentros comerciales abandonaron el negocio y eso aceleró el declive de las ferias (Acosta, 2014: 8).

30 Reglamento de Jefes Políticos, Municipalidades y Alcaldes, 4 de septiembre de 1832 (Menéndez, 1855: 163-164, citado en Méndez, 2018: 207). 
La caída del comercio del añil fue la decadencia de una actividad económica y agrícola que se mantuvo en auge desde la época colonial (Fernández M., 2003). En contraste ocurrió que los granos del café empezaran a marcar la pauta para el comercio y los ingresos fiscales de El Salvador. Este cambio implicó la transformación en las dinámicas comerciales internas y externas del país, además de impactar en las estructuras agrarias y la organización del trabajo de las comunidades y los pueblos (Acosta, 2014; Méndez, 2018; Pérez, 2012).

La transición del comercio de añil al de café también se reflejó en las dinámicas sociales. Este aspecto poco explorado por la historiografía permite localizar testimonios de primera mano de aquellos fenómenos que incumben al ámbito comercial, pero que, irremediablemente, muestran las actividades sociales y la adopción de estrategias de los actores involucrados en la realización de los encuentros feriales, sobre todo en los momentos coyunturales de reorganización económica e institucional.

\section{Consideraciones finales}

Esta revisión de las ferias comerciales de Guatemala y El Salvador durante el siglo XIX se propone abrir espacios de discusión para establecer líneas que permitan explorar los procesos históricos centroamericanos a la luz de las fuentes hemerográficas, especialmente aquellas vinculadas con la historia cultural y la vida cotidiana, que puedan dialogar con una historiografía sobre Centroamérica y el sureste de México que ya ha recurrido a la prensa como herramienta metodológica para abordar la historia de la ciencia, las ideas políticas y la economía (Claps, 2011; 2017; Hernández, 2015).

En este aspecto, los impresos y periódicos de Guatemala y El Salvador del siglo XIX permiten realizar este tipo de ejercicios. La relativa abundancia de estas herramientas que se encuentran diseminadas por los archivos, bibliotecas y repositorios electrónicos en México, Estados Unidos de América, Centroamérica y Europa son una invitación a retomar lo que parecieran ser detalles de la historia, pero que son contenidos temáticos poco explorados, ubicados en notas periodísticas, informes y editoriales. Estos elementos son importantes porque posibilitan leer entre líneas otros aspectos de la vida cotidiana, la economía, las creencias e identidades, las diversiones públicas, los miedos y los gozos de una sociedad inmersa en una dinámica de transformación y continuidad, producto de los procesos políticos, económicos, étnicos y religiosos. 
Estas historias particulares sobre el siglo XIX enriquecen los análisis de los procesos políticos que hasta la fecha conocemos. Ahora, resulta necesario ampliar el conocimiento sobre las diversiones públicas, las costumbres religiosas, la vida cotidiana (Carey y Taylor, 2012; Reeves, 2012) y, ¿por qué no?, del amor y la muerte en esos contextos (Komisaruk, 2013). Otra temática que está pendiente de ser abordada es la historia de las mujeres. Las fuentes para realizar esas pesquisas también se encuentran fragmentadas, pero listas para ser hiladas en el discurso histórico. Al respecto, expuse el papel de las "plazeras" como agentes comerciales en pequeña escala. No obstante, me quedaron más preguntas sobre ellas: ¿quiénes eran realmente? ¿cómo estaban organizadas? y ¿cómo llegaron a controlar esos espacios? Especialmente, si pensamos que las ferias eran un hervidero de personas sometidas a un ir y venir constante de ideas y noticias que circulaban de boca en boca.

Finalmente, resulta interesante cuestionar la función de estos encuentros como una herramienta que contribuyó a la consolidación de los gobiernos nacionales durante el siglo XIX. Aunque se han realizado algunas aproximaciones para el caso de El Salvador (López, 2011), falta indagar sobre su influencia en los espacios locales, donde la vida cotidiana se entretejía con las manifestaciones políticas trastocadas por las convulsiones sociales y militares del siglo XIX centroamericano. Incluso, ampliar la mirada de forma comparativa hacia otros territorios contiguos como Honduras, Nicaragua y el sureste de México. Este ejercicio podría arrojar interesantes datos comparativos.

De este modo, el estudio de las ferias nos arroja elementos de análisis comparativo en Centroamérica, sobre todo de aquellos territorios que experimentaron la transición de cultivos "tradicionales" como el añil y la grana cochinilla hacia el café. El comercio cafetalero y el proceso de modernización capitalista emprendido en Guatemala y El Salvador prescindió de esos encuentros para su comercialización. De este modo, las ferias comerciales fueron desplazadas en su función, y paulatinamente quedaron relegadas, para ser espacios de esparcimiento social. Sin embargo, algunas se mantuvieron como testimonios de las citas comerciales decimonónicas. 


\section{Bibliografía citada}

\section{Fuentes primarias}

El Diario del Salvador

El Guatemalteco

El Noticioso

El Progreso

El Siglo y Regeneración

El Tiempo

Gaceta de Guatemala

La Gaceta del Gobierno del Salvador

\section{Fuentes secundarias}

Acosta Rodríguez, Antonio. (2013). Una república agraria: los campesinos en la economía y la política de El Salvador en el siglo XIX. San Salvador: CONCULTURA.

Acosta Rodríguez, Antonio. (2014). Los orígenes de la burguesía de El Salvador. El control sobre el café y el Estado, 1848-1890. Sevilla: Universidad de Barcelona/Universidad de Sevilla/Aconcagua Libros.

Acosta Rodríguez, Antonio. (2015). "De vagos a comunistas: la imagen de la mano de obra rural en la mentalidad oligárquica de El Salvador en los siglos XIX y XX", en Pilar García Jordán (ed.) El mundo latinoamericano como representación, siglos XIX-XX. Barcelona: Publicacions i Edicions de la Universitat de Barcelona, pp. 107-131.

Acuña Ortega, Víctor Hugo. (2015). "Centroamérica en las globalizaciones (siglos XVIXXI)", Anuario de Estudios Centroamericanos, 41, pp. 13-27.

Avendaño Rojas, Xiomara. (2019) "La figura del jefe político departamental en Guatemala, El Salvador y Nicaragua durante la primera mitad del siglo XIX", Rúbrica Contemporánea, VIII(15), pp. 46-66.

Cambranes, Julio Castellanos (1985). Café y campesinos en Guatemala, 1853-1897. Guatemala: Editorial Universitaria de Guatemala.

Carey, David y William B. Taylor. (2012). Distilling the Influence of Alcohol: Aguardiente in Guatemalan History. Gainesville: University Press of Florida.

Castellón Osegueda, José Ricardo (2016). "De la hacienda a los puertos. Los caminos en los primeros años de la república del Salvador. Siglo XVIII", Revista de Humanidades y Ciencias Sociales, 7, II época, San Salvador, enero-junio, pp. 115-142.

Cipolla, Carlo M. (1991). Entre la historia y la economía. Barcelona: Crítica.

Claps Arenas, Ma. Eugenia. (2011). "El Iris de Chiapas y los ayuntamientos", en Rocío Ortiz Herrera y Carlos Uriel del Carpio Penagos (coords.). Seis ensayos sobre historia de Centroamérica. Colección Selva Negra. México: Universidad de Ciencias y Artes de Chiapas (UNICACH), pp. 125-140. 
Claps Arenas, Ma. Eugenia. (2017). "El Siglo de Lafayette y su discurso sobre México", Revista Pueblos y fronteras digital, 12(24), diciembre, pp. 23-42.

Connaughton, Brian. (coord.) (2017). Repensando Guatemala en la época de Rafael Carrera. El país, el hombre y las coordenadas de su tiempo. México: Editorial Gedisa/Universidad Autónoma Metropolitana (UAM).

Dary Fuentes, Claudia. (1993). Diversiones populares en la ciudad de Guatemala: circos y funambulistas, 1847-1898. Guatemala: Centro de Estudios Folclóricos (CEFOL)-Universidad de San Carlos de Guatemala (USAC).

Fernández Marroquín, Vitalino. (1985). Apuntes históricos de Esquipulas. Guatemala: Ministerio de Educación.

Fernández Molina, José Antonio. (2003). Pintando el mundo de azul, el auge añilero y el mercado centroamericano, 1750-1810. El Salvador: Biblioteca de Historia Salvadoreña, 14, CONCULTURA.

Gobierno de Guatemala, (1879). Ley orgánica del gobierno político de los departamentos de la República de Guatemala. Guatemala: Tipografía El Progreso.

González Sandoval, Leticia. (2014). "Embriaguez y hacienda pública en Guatemala, 18401865: entre la moral decimonónica y los ingresos fiscales", Vegueta, Anuario de la Facultad de Geografía e Historia, vol. 14, pp. 271-288.

González-lzás, Matilde. (2014). Modernización capitalista, racismo y violencia. Guatemala (1750-1930). México: El Colegio de México.

Gould, Jeffrey L. y Aldo Lauria-Santiago. (2008). 1932: Rebelión en la oscuridad. San Salvador: Museo de la Palabra y la Imagen.

Hernández Pérez, José Santos. (2015). La Gaceta de Guatemala: un espacio para la difusión del conocimiento científico, 1797-1804. México: UAM.

Herrera Alfaro, Sara y María Eugenia Rojas Rodríguez. (1998). "El añil en Centroamérica siglos XVII-XVIII", Revista Estudios, 15, pp. 41-55.

Jovel, Roberto. (2001). Las monedas de necesidad de Guatemala, siglos XVII a XIX. Santiago de Chile: LOM Ediciones, pp. 60-71.

Kendall, Carl. (1991). "The Politics of Pilgrimage: The Black Christ of Esquipulas" en N. Ross Crumrine y Alan Morinis (eds.). Pilgrimage in Latin America. Westport, CT: Greenwood Press, pp. 139-156.

Komisaruk, Catherine. (2013). Labor and Love in Guatemala: The Eve of Independence. United States of America: Stanford University Press.

Larde y Larin, Jorge. (1950). Recopilación de leyes relativas a la historia de los municipios de El Salvador. San Salvador: Ministerio del Interior.

Lauria Santiago, Aldo. (1995). "Los indígenas de Cojutepeque, la Política faccional y el Estado nacional en El Salvador, 1830-1890", en Arturo Taracena y Jean Piel (comps.) Identidades nacionales y Estado moderno en Centroamérica. San José. Costa Rica: Editorial de la Universidad de Costa Rica, pp. 237-252.

Lindo-Fuentes, Héctor. (1995). "The Economy of Central America: From Bourbon Reforms to Liberal Reforms", en Lowell Gudmundson y Héctor Lindo-Fuentes, Central America, 1821-1871. Liberalism before Liberal Reform. Tuscaloosa y Londres: The University of Alabama Press, pp. 13-76. 
López Bernal, Carlos Gregorio. (2011). Mármoles, clarines y bronces. Fiestas cívico-religiosas en El Salvador, siglos XIX-XX. San Salvador. El Salvador: Editorial Universidad Don Bosco/Secretaría de Cultura de la Presidencia (Serie Bicentenario, Colección Investigación).

Luján Muñoz, Jorge. (1980). Economía de Guatemala, 1750-1940. Antología de lecturas y materiales. Guatemala: Facultad de Humanidades-USAC.

Marure, Alejandro. (1841). Catálogo de las leyes promulgadas en el estado de Guatemala, desde su erección en 15 de septiembre de 1821 hasta el 5 de octubre de 1841. Guatemala: Imprenta de la Paz.

Méndez Zárate, Armando. (2018). Estructuras agrarias, territorio y trabajo: La "Bocacosta" centroamericana (Soconusco, Guatemala y El Salvador), 1821-1890. Tesis de doctorado en Historia, México: Centro de Investigaciones y Estudios Superiores en Antropología Social.

Menéndez, Isidro. (1855) Recopilación de las leyes del Salvador. Tomo I. Guatemala: Imprenta de L. Luna.

Monterey, Francisco J. (1996). Historia de El Salvador: 1810-1842. Tomo I. San Salvador: Editorial Universitaria, Universidad de El Salvador.

Moziño, José Mariano. (1799). Tratado del Xiquilite y Añil de Guatemala. Dedicado a su real sociedad económica. Guatemala: Medina J. T.

Paz Solorzano, Juan. (1904). Documentos históricos referentes a la sagrada imagen del señor crucificado de Esquipulas y de su santuario. Guatemala: Tipografía de Sánchez y de Guise.

Pérez Fabregat, Clara. (2011). "La organización del municipio salvadoreño entre 1840 y 1869. Una aproximación a la construcción del Estado desde el ámbito local", Boletín Americanista, año LXI, 1(62), pp. 201-218.

Pérez Fabregat, Clara. (2012). "La configuración del espacio económico en el marco de la construcción del Estado: el Oriente salvadoreño, 1840-1855", Revista Complutense de Historia de América, 38, pp. 129-151.

Pérez Fabregat, Clara. (2018). San Miguel y el oriente salvadoreño. La construcción del Estado de El Salvador, 1780-1865. San Salvador. El Salvador: UCA Editores.

Pinto Morán, María del Carmen. (2012). La feria del Cristo Negro de Esquipulas en Guatemala, 1770-1845: espiritualidad, diversión y comercio. Tesis de maestría en Historia. Guatemala: USAC.

Reeves, René. (2012). "From Household to Nation: The Economic and political Impact of Woman and Alcohol in Nineteenth-Century Guatemala", en David Carey y William Taylor (eds.), Distilling the Influence of Alcohol: Aguardiente in Guatemalan History. Gainesville: University Press of Florida.

Rodríguez Oromendía, Ainhoa, Azahara Muñoz Martínez y Demetrio González Crespo. (2013). "Historia, definición y legislación de las ferias comerciales". Anuario Jurídico y Económico Escurianlense, vol. XLVI, pp. 449-466.

Rubio Sánchez, Manuel. (1976). Historia del añil o xiquilite en Centro América. San Salvador. El Salvador: Ministerio de Educación.

Sagastume Paiz, Tania. (2015). "Vagos, ociosos y mal entretenidos. La permanencia de la reforma de las costumbres en Guatemala a mediados del siglo XIX", en Brian 
Connaughton (coord.). Repensando Guatemala en la época de Rafael Carrera. El país, el hombre y las coordenadas de su tiempo. México: Editorial Gedisa/UAM, pp. 389-430.

Sarazúa Pérez, Juan Carlos. (2007). Territorialidad, comercio y conflicto al Este de Guatemala: Santa Rosa, 1750-1871, Tesis de licenciatura. Guatemala: USAC.

Sarazúa Pérez, Juan Carlos. (2013). Recolectar, administrar y defender: la construcción del Estado y las resistencias regionales en Guatemala, 1800-1871. Tesis de doctorado. Barcelona: Universitat Pompeu Fabra.

Sarazúa Pérez, Juan Carlos. (2018). "Bandoleros y políticas en Chiapas y Guatemala, 18251850", Península, XIII(2), julio-diciembre, pp. 43-67.

Sin Autor (1840). Contestaciones entre el Gobierno de Guatemala y el del Salvador sobre el derecho de veinte por ciento que impuso. Guatemala: Imprenta del Estado.

Torres Freyermuth, Amanda Úrsula. (2020). "El comercio y la producción económica de Chiapas en los documentos del estado, 1825-1880", en Aaron Pollack, Amanda Úrsula Torres Freyermuth, Juan Carlos Sarazúa y María Dolores Infante Palomo (eds.) Historias e historiografías del siglo XIX en Chiapas y Guatemala. San Cristóbal de Las Casas, Chiapas: Centro de Investigaciones Multidisciplinarias sobre Chiapas y la Frontera Sur (CIMSUR-UNAM), pp. 149-177.

Urbina Gaitán, Chester. (2002). "Teatro, Estado y promoción cultural en Guatemala, 18751921", Anuario de Estudios Centroamericanos, 32, pp. 81-95.

Woodward, Ralph Lee. (2002). Rafael Carrera y la creación de la república de Guatemala, 1821-1871. South Woodstock: Plumsock Mesoamerican Studies, CIRMA.

\section{Cómo citar este artículo:}

Méndez Zárate, Armando (2022), «Ferias comerciales en Guatemala y El Salvador vistas por la prensa del siglo XIX». Revista Pueblos y fronteras digital, 17, pp.1-25, doi: 10.22201/ cimsur.18704115e.2022.v17.531. 